\title{
Distal Femur R1
}

National Cancer Institute

\section{Source}

National Cancer Institute. Distal Femur R1. NCI Thesaurus. Code C139208.

The portion of the distal femur, identified during a DXA scan, that contains primarily metaphyseal or trabecular bone. 